\title{
Mesenchymal Stem Cells Alter the Inflammatory Response of C2C12 Mouse Skeletal Muscle Cells
}

\author{
Yusuke Kono, ${ }^{*, a, b}$ Akihiro Miyamoto, ${ }^{b}$ Serina Hiraoka, ${ }^{b}$ Ryosuke Negoro, ${ }^{b}$ and Takuya Fujita ${ }^{a, b, c}$ \\ ${ }^{a}$ Ritsumeikan-Global Innovation Research Organization, Ritsumeikan University; 1-1-1 Noji-Higashi, Kusatsu, Shiga \\ 525-8577, Japan: ${ }^{b}$ Laboratory of Molecular Pharmacokinetics, College of Pharmaceutical Sciences, Ritsumeikan \\ University; 1-1-1 Noji-Higashi, Kusatsu, Shiga 525-8577, Japan: and ${ }^{c}$ Research Center for Drug Discovery and \\ Development, Ritsumeikan University; 1-1-1 Noji-Higashi, Kusatsu, Shiga 525-8577, Japan. \\ Received July 1, 2020; accepted August 23, 2020
}

\begin{abstract}
Mesenchymal stem cells (MSCs) are capable of repairing skeletal muscle via paracrine mechanisms. This regenerative effect of MSCs on skeletal muscle is based on promoting the proliferation and differentiation of myogenic cells and inhibiting the inflammatory response of immune cells. However, it is unclear whether MSCs affect the inflammatory response of skeletal muscle cells. In this study, we evaluated the paracrine effect of mouse MSCs on the inflammatory response of lipopolysaccharide (LPS)-stimulated C2C12 mouse myoblasts. Interleukin (IL)-6 production from LPS-stimulated C2C12 cells was significantly increased by coculture with MSCs or culture in conditioned medium of MSCs. This increased IL-6 production from C2C12 cells was not significantly suppressed by inhibiting mitogen-activated protein kinase pathways, but it was significantly suppressed by pretreatment with nuclear factor $-\kappa \mathrm{B}(\mathrm{NF}-\kappa \mathrm{B})$ and signal transducer and activator of transcription 3 (STAT3) inhibitors. In addition, IL-6 and inducible nitric oxide synthase (iNOS) mRNA expression was increased significantly in $\mathrm{C} 2 \mathrm{C} 12$ cells cocultured with MSCs, while tumor necrosis factor (TNF)- $\alpha$ and IL-1 $\beta$ mRNA expression was decreased. Furthermore, conditioned medium of C2C12 cells cocultured with MSCs exerted remarkable anti-inflammatory effects on LPS-stimulated mouse macrophages.
\end{abstract}

Key words mesenchymal stem cell; skeletal muscle; inflammatory response; interleukin (IL)-6

\section{INTRODUCTION}

Mesenchymal stem cells (MSCs) are multipotent progenitor cells that can be isolated from various tissues including bone marrow, adipose tissue, umbilical cord, and placenta., ${ }^{1,2}$ MSCs have the capacity to differentiate into mesodermal cell lineages, such as osteoblasts, chondrocytes, and adipocytes, as well as endodermal and ectodermal cell lineages including hepatocytes and neuronal cells. In addition to their multipotency, MSCs secrete immunomodulation factors, such as hepatocyte growth factor (HGF), insulin-like growth factor (IGF), and transforming growth factor- $\beta$, which facilitate tissue repair. ${ }^{3,4)}$ Therefore, MSCs are promising therapeutic agents for tissue injury and disorders such as myocardial infarction, liver fibrosis, and Alzheimer's disease.

In the last decade, MSCs have been shown to regenerate skeletal muscle and restore its function. ${ }^{5,6)}$ Several reports have demonstrated that intramuscular injection of MSCs significantly improves the fast twitch and tetanic contraction forces of skeletal muscle after muscle trauma in rats. ${ }^{7,8)}$ In addition, systemic injection of MSCs enhances functional recovery of injured muscles in animals. ${ }^{9)}$ Thus, MSC-based cell therapy would provide exciting possibilities for treating muscle disabilities such as sarcopenia and frailty.

More recently, the regenerative effect of MSCs on skeletal muscle was identified to be mediated by paracrine mechanisms rather than differentiation of MSCs into skeletal muscle cells. ${ }^{5,6)} \mathrm{Kim}$ et al. reported that umbilical cord MSC-derived conditioned medium recovers the status and function of atrophied muscle in mice. ${ }^{10)}$ Moreover, Nakamura et al. demonstrated that MSC-derived exosomes promote the proliferation and differentiation of myoblasts, resulting in accelerated muscle regeneration in a mouse muscle injury model. ${ }^{11)}$ Although it is still unclear which secreted factors from MSCs mainly contribute to muscle regeneration, several reports have shown that IGF-1 prevents loss of muscle mass and induces muscle hypertrophy. ${ }^{12,13)}$ HGF also promotes activation of satellite cells and migration of myogenic precursor cells. ${ }^{12,14)}$ In addition to these direct effects on skeletal muscle cells, the secreted factors from MSCs contribute to muscle repair via immunomodulation of immune cells. MSC-derived soluble factors suppress the formation and proliferation of $\mathrm{CD}_{4}{ }^{+}$and $\mathrm{CD}_{8}{ }^{+}$ $\mathrm{T}$ cells. Moreover, the soluble factors from MSCs promote induction of regulatory $\mathrm{T}$ cells. ${ }^{1,5,6)}$ Because muscle injury and disability are frequently accompanied by inflammation, ${ }^{5,6}$ the anti-inflammatory effect of MSCs may facilitate recovery of tissue homeostasis and cellular functions in skeletal muscle. Thus, MSCs exert regenerative effects on skeletal muscle by promoting the proliferation and differentiation of myogenic cells and inhibiting the inflammatory response of immune cells. However, there are few reports demonstrating the effect of MSCs on the inflammatory response of skeletal muscle cells. Because the direct immunomodulatory effect of MSCs on skeletal muscle cells is crucial for muscle regeneration, we considered that elucidating how MSCs affect the inflammatory response of skeletal muscle cells is important for effective and safe use of MSCs in muscle regenerative therapy.

In this study, we evaluated the paracrine effect of MSCs on the inflammatory responses of murine $\mathrm{C} 2 \mathrm{C} 12$ myoblasts by measuring the protein and mRNA expression levels of inflammatory cytokines and inducible nitric oxide synthase (iNOS). Moreover, we investigated the mechanisms of the altered in- 
flammatory responses of $\mathrm{C} 2 \mathrm{C} 12$ cells by MSCs.

\section{MATERIALS AND METHODS}

Ethics Approval All animal experiments were carried out in accordance with the Guide for the Care and Use of Laboratory Animals of the U.S. National Institutes of Health (Bethesda, MD, U.S.A.) and the Guidelines for Animal Experiments of Ritsumeikan University (Shiga, Japan). The Ritsumeikan University Animal Experimentation Committee approved all protocols for animal experiments. All efforts were made to minimize suffering.

Cell Culture $\mathrm{C} 2 \mathrm{C} 12$ mouse myoblasts were provided by the RIKEN BioResource Center Cell Bank (Ibaraki, Japan). C57BL/6 mouse MSCs were purchased from Cyagen Biosciences Inc. (Santa Clara, CA, U.S.A.). C2C12 cells and MSCs were cultured in Dulbecco's modified Eagle's medium (DMEM) supplemented with 10\% heat-inactivated fetal bovine serum, penicillin $\mathrm{G}(100 \mathrm{U} / \mathrm{mL})$, and streptomycin $(100 \mu \mathrm{g} / \mathrm{mL})$ at $37^{\circ} \mathrm{C}$ with $5 \% \mathrm{CO}_{2}$.

Mouse peritoneal macrophages were harvested according to our previous report. ${ }^{15)}$ In brief, 6-week-old male C57BL/6 mice were intraperitoneally injected with $1 \mathrm{~mL}$ of $2.9 \%$ thioglycolate medium. Four days after the injection, macrophages were collected from the peritoneal cavity, and seeded on 6-well culture plates at $3 \times 10^{5}$ cells $/ \mathrm{cm}^{2}$ in RPMI-1640 medium supplemented with $10 \%$ heat-inactivated fetal bovine serum, penicillin $\mathrm{G}(100 \mathrm{U} / \mathrm{mL})$, and streptomycin $(100 \mu \mathrm{g} / \mathrm{mL})$.

Measurement of Interleukin (IL)-6 Production from C2C12 Cells Cocultured with MSCs C2C12 cells were seeded in 6 -well plates at $2 \times 10^{4}$ cells $/ \mathrm{cm}^{2}$ and cultured for $48 \mathrm{~h}$. To induce differentiation of $\mathrm{C} 2 \mathrm{C} 12$ cells into myotubes, the culture medium was replaced with DMEM supplemented with $2 \%$ heat-inactivated horse serum, penicillin $G$ $(100 \mathrm{U} / \mathrm{mL})$, and streptomycin $(100 \mu \mathrm{g} / \mathrm{mL})$. The medium was replaced every other day. MSCs were seeded on a 6-well cell culture insert at $2 \times 10^{4}$ cells $/ \mathrm{cm}^{2}$ and cultured for $48 \mathrm{~h}$. After $5 \mathrm{~d}$ of differentiation, $\mathrm{C} 2 \mathrm{C} 12$ cells were cocultured with MSCs and stimulated with $100 \mathrm{ng} / \mathrm{mL}$ lipopolysaccharide (LPS). The culture supernatants of $\mathrm{C} 2 \mathrm{C} 12$ cells were collected at predetermined time points, and the IL- 6 concentration was measured using an enzyme-linked immunosorbent assay (ELISA) kit (Thermo Fisher Scientific, Waltham, MA, U.S.A.).

Measurement of IL-6 Production from C2C12 Cells and MSCs Cultured in Each Conditioned Medium Differentiated $\mathrm{C} 2 \mathrm{C} 12$ cells and MSCs seeded in 100-mm dishes were stimulated with $100 \mathrm{ng} / \mathrm{mL}$ LPS for $24 \mathrm{~h}$. Each conditioned medium was collected and passed through a $0.45-\mu \mathrm{m}$ membrane filter. Then, differentiated $\mathrm{C} 2 \mathrm{C} 12$ cells and MSCs in 6-well plates were incubated in each conditioned medium, followed by LPS stimulation at $100 \mathrm{ng} / \mathrm{mL}$. When the inhibitory effects of mitogen-activated protein kinase (MAPK) cascades were evaluated, differentiated $\mathrm{C} 2 \mathrm{C} 12$ cells in 6-well plates were pretreated with the p38 inhibitor SB203580 $(30 \mu \mathrm{M})$, c-jun $\mathrm{NH}_{2}$-terminal kinase (JNK) inhibitor SP600125 $(100 \mu \mathrm{M})$, or MAPK kinase (MEK) inhibitor PD98059 $(100 \mu \mathrm{M})$ for $1 \mathrm{~h}$. Similarly, to evaluate involvement of nuclear factor- $\kappa \mathrm{B}$ $(\mathrm{NF}-\kappa \mathrm{B})$ and signal transducer and activator of transcription 3 (STAT3) signaling, the cells were pretreated with the NF- $\kappa \mathrm{B}$ inhibitor BAY11-7082 $(10 \mu \mathrm{M})$ or STAT3 inhibitor napabuca$\sin (1 \mu \mathrm{M})$ for $1 \mathrm{~h}$ or $1 \mathrm{~d}$, respectively. The culture supernatants were collected at predetermined time points, and the IL-6 ELISA was carried out. The IL- 6 concentration was corrected by subtracting the IL- 6 concentration in the conditioned medium from that in the culture supernatants.

Measurement of NF- $\kappa \mathrm{B}$ and STAT3 in C2C12 Cells Cultured in Each Conditioned Medium of MSCs Differentiated $\mathrm{C} 2 \mathrm{C} 12$ cells in 6-well plates were pretreated with or without BAY11-7082 $(10 \mu \mathrm{M})$ or napabucasin $(1 \mu \mathrm{M})$ for $1 \mathrm{~h}$ or $1 \mathrm{~d}$, respectively. Then, the cells were incubated in conditioned medium of MSCs under LPS stimulation $(100 \mathrm{ng} / \mathrm{mL})$ for $24 \mathrm{~h}$. The cells were collected, and analyzed for total and phosphorylated NF- $\kappa$ B p65 and STAT3 using InstantOne ${ }^{\mathrm{TM}}$ ELISA kits (Thermo Fisher Scientific) according to manufacturer instructions. The phosphorylated NF- $\kappa \mathrm{B}$ p 65 and STAT3 levels were normalized with respect to the total NF- $\kappa \mathrm{B}$ p 65 and STAT3 levels, respectively.

Real-Time RT-PCR After coculture of differentiated C2C12 cells with MSCs for predetermined times under LPS stimulation $(100 \mathrm{ng} / \mathrm{mL})$, total RNA was isolated from $\mathrm{C} 2 \mathrm{C} 12$ cells using Sepasol ${ }^{\mathbb{R}}$-RNA I Super G (Nacalai Tesque, Kyoto, Japan). Reverse transcription was performed using a ReveTra Ace $^{\circledR}$ qPCR RT kit (Toyobo, Osaka, Japan) with oligo(dT) and random primers. The resultant cDNA was measured using PowerUp SYBR Green Master Mix (Thermo Fisher Scientific) and a StepOne Real-Time PCR System (Thermo Fisher Scientific). Target mRNA expression levels were normalized to the mRNA expression level of glyceraldehyde 3-phosphate dehydrogenase (GAPDH). The primers for IL-6, tumor necrosis factor- $\alpha$ (TNF- $\alpha)$, IL- $1 \beta$, iNOS, and GAPDH are listed in Table 1.

Measurement of TNF- $\alpha$ and Nitric Oxide (NO) Secretion from Macrophages Cultured in Conditioned Medium of C2C12 Cells Cocultured with MSCs Differentiated C2C12 cells seeded in 6-well plates were cocultured with or without MSCs, followed by LPS stimulation $(100 \mathrm{ng} / \mathrm{mL})$ for $24 \mathrm{~h}$. The conditioned media were collected and passed through a $0.45 \mu \mathrm{m}$ membrane filter. Mouse peritoneal macrophages were seeded on 6-well cell culture plates, and the culture medium was replaced with the conditioned media of $\mathrm{MSCs}, \mathrm{C} 2 \mathrm{C} 12$ cells, or $\mathrm{C} 2 \mathrm{C} 12$ cells cocultured with MSCs. Then, LPS was added to each well at a final concentration of $100 \mathrm{ng} / \mathrm{mL}$. The culture supernatants were collected at $24 \mathrm{~h}$ after LPS stimulation, and IL- 6 and IL- $1 \beta$ concentrations were measured by ELISAs. The NO concentration in the supernatants was also measured by the Griess assay according to our previously reported procedure. ${ }^{15)}$

Statistical Analysis The results are presented as the mean

Table 1. Primer Sequences for Real-Time RT-PCR

\begin{tabular}{cll}
\hline \hline Gene & & \multicolumn{1}{c}{ Primer sequence $\left(5^{\prime} \rightarrow 3^{\prime}\right)$} \\
\hline \multirow{2}{*}{ Il-6 } & Forward: & 5'-CCG GAG AGG AGA CTT CAC AG-3' \\
& Reverse: & 5'-CAG AAT TGC CAT TGC ACA AC-3' \\
Tnf- $\alpha$ & Forward: & 5'-CCC CAA AGG GAT GAG AAG TT-3' \\
& Reverse: & 5'-CAC TTG GTG GTT TGC TAC GA-3' \\
Il-1 $1 \beta$ & Forward: & 5'-GGA TGA GGA CAT GAG CAC CT-3' \\
& Reverse: & 5'-AGC TCA TAT GGG TCC GAC AG-3' \\
inos & Forward: & 5'-GTT CTC AGC CCA ACA ATA CAA GA-3' \\
& Reverse: & 5'-GTG GAC GGG TCG ATG TCA C-3' \\
\multirow{2}{*}{ Gapdh } & Forward: & 5'-ACA GCA GTG TGC AGT TGA TGA-3' \\
& Reverse: & 5'-GGC AGT CAT GTC CGG TGA TG-3' \\
\hline
\end{tabular}


(A)

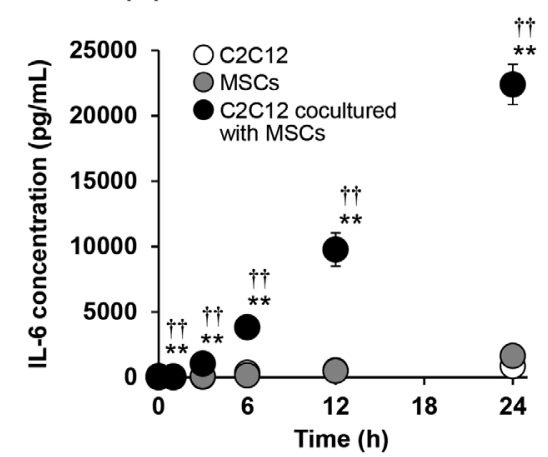

(B)

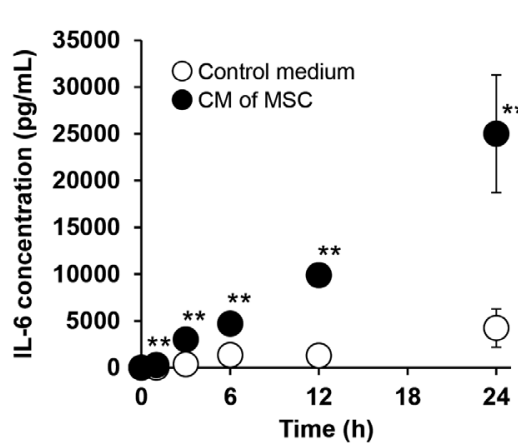

(C)

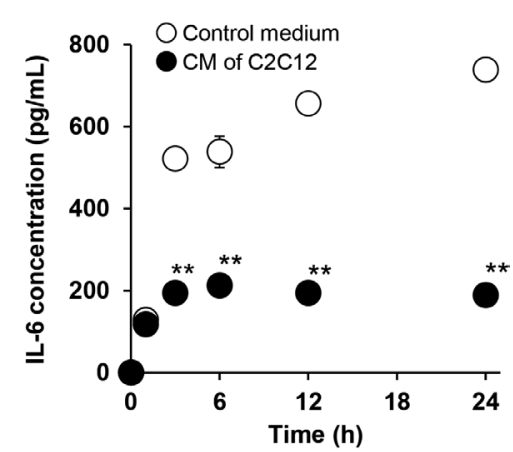

Fig. 1. IL-6 Production from C2C12 Cells Cocultured with MSCs or Cultured in Conditioned Medium of MSCs under LPS Stimulation

(A) IL-6 concentration in culture supernatants of $\mathrm{C} 2 \mathrm{C} 12$ cells cocultured with MSCs under LPS stimulation (100ng/mL). Each value represents the mean \pm standard deviation (S.D.) $(n=4) .{ }^{*} p<0.01$, compared with $\mathrm{C} 2 \mathrm{C} 12 .{ }^{\dagger \dagger} p<0.01$, compared with MSCs. IL-6 concentration in culture supernatants of C2C12 cells (B) and MSCs (C) cultured in each conditioned medium (CM) with LPS stimulation (100 ng/mL). CM was obtained from C2C12 cells or MSCs cultured for $24 \mathrm{~h}$ under LPS stimulation $(100 \mathrm{ng} / \mathrm{mL})$. Each value represents the mean \pm S.D. $(n=4)$. ** $p<0.01$, compared with control medium.

$+/ \pm$ standard deviation (S.D.) of four experiments. Analysis of variance was used to test the statistical significance of differences between groups. Two-group comparisons were performed using the Student's $t$-test. Multiple comparisons between control groups and other groups were performed using Dunnett's test, and those between all groups were carried out using the Tukey-Kramer test.

\section{RESULTS}

Effect of the Coculture of C2C12 Cells with MSCs on Cytokine Production We first evaluated the effect of coculture of $\mathrm{C} 2 \mathrm{C} 12$ cells with MSCs on their inflammatory cytokine production. Both $\mathrm{C} 2 \mathrm{C} 12$ cells and MSCs secreted IL-6 after LPS stimulation in a time-dependent manner (Fig. 1A). When these cells were cocultured, the IL- 6 concentration in culture supernatants was increased remarkably. However, other proinflammatory cytokines, TNF- $\alpha$, and IL- $1 \beta$, and NO were not detected in the culture supernatants of LPS-stimulated $\mathrm{C} 2 \mathrm{C} 12$ cells cocultured with or without MSCs (data not shown).

To clarify that the increased IL-6 concentration in the coculture of $\mathrm{C} 2 \mathrm{C} 12$ cells with $\mathrm{MSCs}$ was attributed to the paracrine effect of MSCs on $\mathrm{C} 2 \mathrm{C} 12$ cells, we investigated IL-6 production from $\mathrm{C} 2 \mathrm{C} 12$ cells and MSCs cultured in each conditioned medium. As shown in Fig. 1B, IL-6 production from $\mathrm{C} 2 \mathrm{C} 12$ cells was increased significantly when the cells were incubated in conditioned medium of MSCs. On the other hand, IL-6 production from MSCs was decreased by incubation in conditioned medium of $\mathrm{C} 2 \mathrm{C} 12$ cells (Fig. 1C). These results indicate that MSCs enhance IL-6 production from C2C12 cells via paracrine mechanisms.

Involvement of MAPK Pathways, and NF- $\kappa$ B and STAT3 Signaling in the Increased IL-6 Production from C2C12 Cells To elucidate the mechanisms of the increased IL-6 production from $\mathrm{C} 2 \mathrm{C} 12$ cells by MSCs, we evaluated the inhibitory effects of p38 MAPK, JNK, and extracellular signal-regulated kinase (ERK) pathways on IL-6 production from LPS-stimulated $\mathrm{C} 2 \mathrm{C} 12$ cells cultured in conditioned medium of MSCs. MAPK signaling pathways are involved in the regulation of IL-6 production from LPS-stimulated skeletal muscle cells. $^{16,17)}$ As shown in Fig. 2A, IL-6 production from $\mathrm{C} 2 \mathrm{C} 12$ cells in control medium was reduced slightly by pretreatment with SB203580 (p38 inhibitor), SP600125 (JNK inhibitor), and PD98059 (MEK inhibitor). Moreover, SB203580 and PD98059 slightly inhibited IL-6 production from C2C12 cells in conditioned medium of MSCs, but it was not significant. Pretreatment with SP600125 did not affect IL-6 production from $\mathrm{C} 2 \mathrm{C} 12$ cells.

Because STAT3 and NF- $\kappa$ B regulate IL-6 expression in skeletal muscle cells, ${ }^{17,18)}$ we assessed the involvement of $\mathrm{NF}-\kappa \mathrm{B}$ and STAT3 signaling in IL-6 production from $\mathrm{C} 2 \mathrm{C} 12$ cells cultured in conditioned medium of MSCs. As shown in Fig. 2B, IL-6 production from $\mathrm{C} 2 \mathrm{C} 12$ cells in control medium and conditioned medium of MSCs was inhibited remarkably by pretreatment with BAY11-7082 (NF- $\kappa$ B inhibitor). Moreover, we observed a significant reduction of IL-6 secretion from LPS-stimulated $\mathrm{C} 2 \mathrm{C} 12$ cells in conditioned medium of MSCs by pretreatment with napabucasin (STAT3 inhibitor) (Fig. 2C). Then, we evaluated the activation of NF- $\kappa \mathrm{B}$ and STAT3 in $\mathrm{C} 2 \mathrm{C} 12$ cells cultured in conditioned medium of MSCs. Both the relative phosphorylated NF- $\kappa$ B p 65 and STAT3 levels in $\mathrm{C} 2 \mathrm{C} 12$ cells were much higher in conditioned medium of MSCs than those in control medium (Figs. 2D, E).

Effect of Coculture of C2C12 Cells with MSCs on Inflammatory Cytokine and iNOS mRNA Expression in C2C12 Cells We also examined the mRNA expression levels of inflammatory markers, IL-6, TNF- $\alpha$, IL- $1 \beta$, and iNOS in $\mathrm{C} 2 \mathrm{C} 12$ cells cocultured with MSCs. IL-6 mRNA expression in LPS-stimulated $\mathrm{C} 2 \mathrm{C} 12$ cells was strongly increased by coculture with MSCs, which remained high until $3 \mathrm{~h}$ after coculture (Fig. 3A). However, TNF- $\alpha$ and IL- $1 \beta$ mRNA expression levels were decreased by approximately 0.5 - and 0.4 -fold until $3 \mathrm{~h}$, respectively (Figs. 3B, C). We also observed that iNOS mRNA expression in $\mathrm{C} 2 \mathrm{C} 12$ cells was increased by approximately 140 -fold at $1 \mathrm{~h}$ after coculture with MSCs under LPS stimulation, which returned to the initial level at $3 \mathrm{~h}$ (Fig. 3D).

Inflammatory Cytokines and NO Production from Macrophages in Conditioned Medium of $\mathrm{C2C12}$ Cells Cocultured with MSCs Because IL-6 regulates the inflammatory response of immune cells, ${ }^{19,20)}$ we considered that the increased IL- 6 production from skeletal muscle cells by paracrine effects of MSCs contributed to the anti-inflammatory effects on immune cells. Therefore, we evaluated production of inflammatory cytokines and $\mathrm{NO}$ from macrophages in conditioned medium of $\mathrm{C} 2 \mathrm{C} 12$ cells cocultured with MSCs. 
(A)
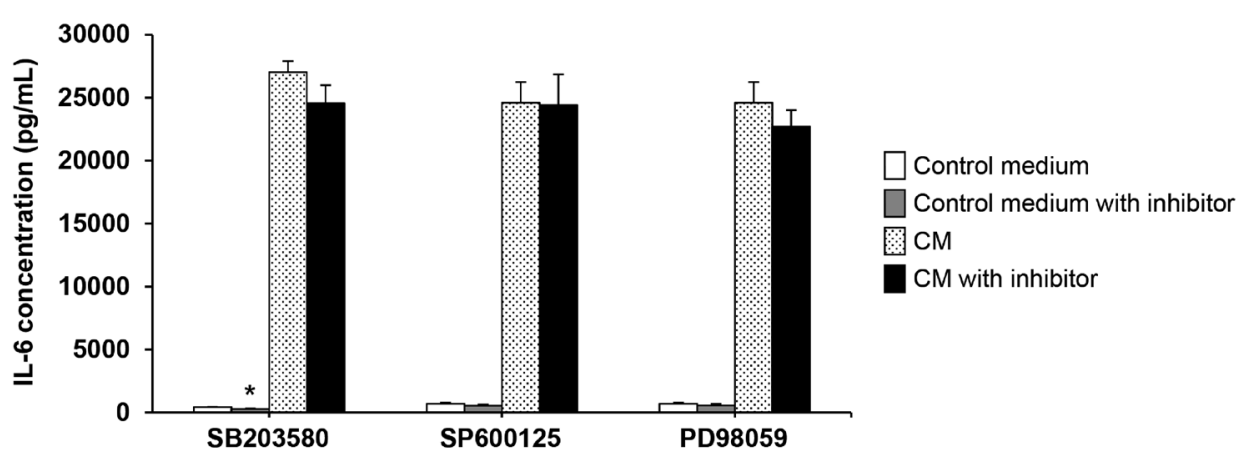

(B)

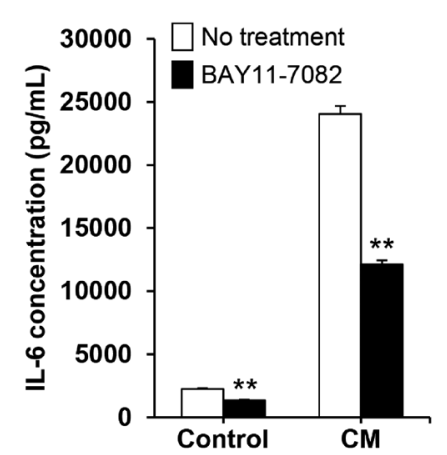

(C)

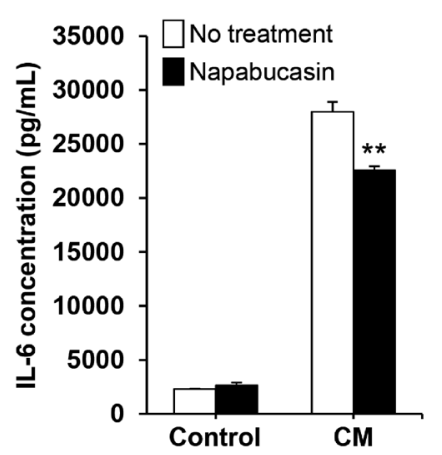

(D)

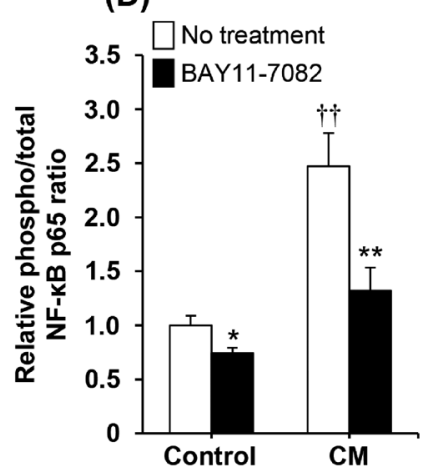

(E)

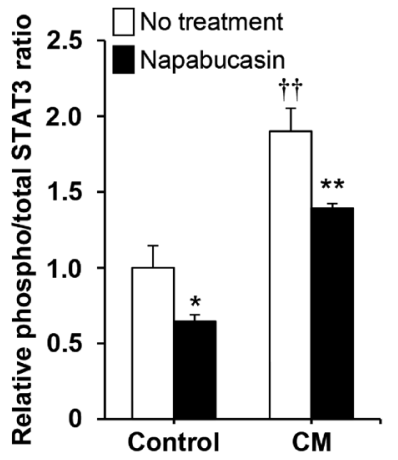

Fig. 2. Inhibitory Effects of MAPK Pathways and NF- $\kappa$ B and STAT3 Signaling on IL-6 Production from C2C12 Cells Cultured in Conditioned Medium of MSCs under LPS Stimulation

IL-6 concentrations were measured in culture supernatants of $\mathrm{C} 2 \mathrm{C} 12$ cells in conditioned medium (CM) of MSCs treated for $24 \mathrm{~h}$ with LPS (100 ng/mL). The cells were pretreated with SB203580 $(30 \mu \mathrm{M})$, SP600125 $(100 \mu \mathrm{M})$, or PD98059 $(100 \mu \mathrm{M})$ for $1 \mathrm{~h}(\mathrm{~A})$, BAY11-7082 $(10 \mu \mathrm{M})$ for $1 \mathrm{~h}(\mathrm{~B})$, or napabucasin $(1 \mu \mathrm{M})$ for $24 \mathrm{~h}(\mathrm{C})$. CM was obtained from MSCs cultured for $24 \mathrm{~h}$ under LPS stimulation $(100 \mathrm{ng} / \mathrm{mL})$. Each value represents the mean + S.D. $(n=4)$. $* p<0.05 ; * * p<0.01$, compared with the corresponding group without an inhibitor. Relative phosphorylated NF- $\kappa \mathrm{B}$ p65 (D) and STAT3 (E) expression levels in C2C12 cells cultured in conditioned medium of MSCs treated for $24 \mathrm{~h}$ with LPS $(100 \mathrm{ng} / \mathrm{mL})$. The phosphorylated NF- $\kappa$ B p 65 and STAT3 levels were normalized with respect to the total NF- $\kappa$ B p65 and STAT3 levels, respectively. Each value represents the mean + S.D. $(n=3)$. ${ }^{*} p<0.05 ; * *<0.01$, compared with the corresponding group without an inhibitor. ${ }^{\dagger} p<0.01$, compared with control without an inhibitor.

As shown in Fig. 4, TNF- $\alpha$, IL-1 $\beta$, and NO production from LPS-stimulated macrophages in conditioned medium of $\mathrm{C} 2 \mathrm{C} 12$ cells was similar to that from macrophages in control medium. However, TNF- $\alpha$ production from macrophages was decreased significantly when macrophages were cultured in conditioned medium of MSCs. IL- $1 \beta$ and NO production was also reduced. More significant suppression of TNF- $\alpha$, IL- $1 \beta$, and NO production from macrophages was observed using conditioned medium of $\mathrm{C} 2 \mathrm{C} 12$ cells cocultured with MSCs.

\section{DISCUSSION}

MSCs have immunosuppressive effects on immune cells. ${ }^{1,5,6)}$ For example, MSCs suppress the formation of not only $\mathrm{CD}^{+}$and $\mathrm{CD}^{+} \mathrm{T}$ cells, but also dendritic cells. Moreover, MSCs induce the generation of $\mathrm{CD}^{+}$regulatory $\mathrm{T}$ cells. These events contribute to reduction of inflammation in skeletal muscle tissue. However, it remained unclear whether MSCs directly affect the inflammatory response of skeletal muscle cells. In this study, we described the change in inflammatory responses of $\mathrm{C} 2 \mathrm{C} 12$ cells by the paracrine effects of MSCs and its mechanisms.

We observed that IL-6 production from LPS-stimulated $\mathrm{C} 2 \mathrm{C} 12$ cells was increased remarkably by coculture with MSCs or culture in conditioned medium of MSCs (Fig. 1). These results indicate that IL-6 production from $\mathrm{C} 2 \mathrm{C} 12$ cells is stimulated by the paracrine effect of MSCs. IL-6 is well recognized as an inflammatory cytokine that plays a substantial role in the transition from innate to adaptive immunity. ${ }^{19,20)}$ IL-6 induces neutrophil apoptosis and enhances the recruitment of monocytes and their differentiation in inflamed tissue. However, IL-6 has also been identified as a major myokine that crucially regulates muscle repair. ${ }^{20)}$ Serrano et al. reported that IL-6 stimulates proliferation of satellite cells that are skeletal muscle progenitor cells. ${ }^{21)}$ In addition, other reports have demonstrated that IL-6 promotes myogenic differentiation of skeletal muscle cells via activation of STAT3. ${ }^{22,23)}$ Based on these findings, we assumed that the increased IL-6 production from $\mathrm{C} 2 \mathrm{C} 12$ cells by the paracrine effect of MSCs is a response to enhance muscle repair rather than promoting inflammation.

We aimed to clarify the mechanisms of the enhancement of IL-6 production from $\mathrm{C} 2 \mathrm{C} 12$ cells. Although LPS stimulates IL-6 expression in skeletal muscle cells by activating MAPK pathways, ${ }^{16,17)}$ only a slight reduction of IL-6 production from $\mathrm{C} 2 \mathrm{C} 12$ cells in control medium was observed after pretreatment with SB203580, SP600125, and PD98059 (Fig. 2A). Because previous reports had used a high concentration of LPS $(1 \mu \mathrm{g} / \mathrm{mL})$ and L6 rat skeletal muscle cells, ${ }^{16,17)}$ we assumed that the difference in the LPS concentration and cell type may contribute to the different results between the present study and previous reports with respect to the regulation 
(A)

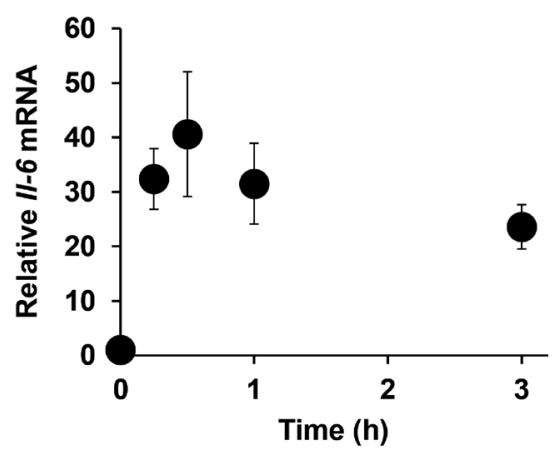

(C)

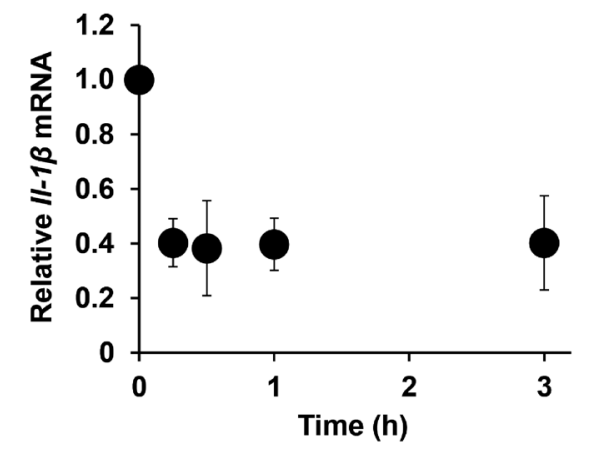

(B)

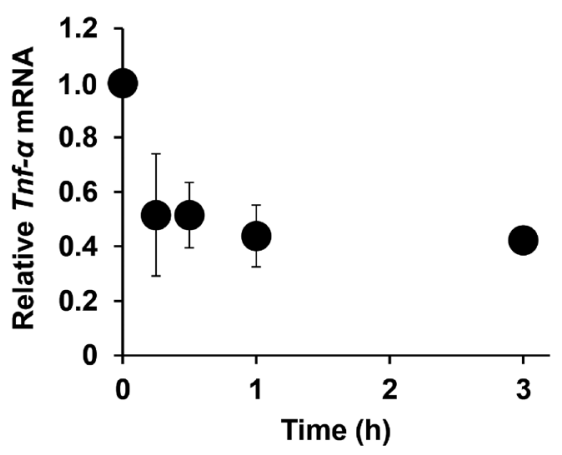

(D)

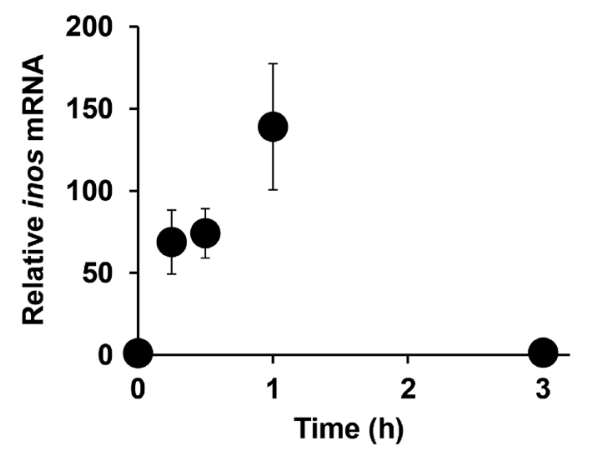

Fig. 3. mRNA Expression Levels of $i l-6$ (A), $t n f-\alpha(\mathrm{B}), i l-1 \beta$ (C), and inos (D) in C2C12 Cells Cocultured with MSCs under LPS Stimulation

Total RNA was isolated from $\mathrm{C} 2 \mathrm{C} 12$ cells at $0.25,0.5,1$, and $3 \mathrm{~h}$ after coculture with MSCs under LPS stimulation (100 ng/mL). Data were normalized to GAPDH. Relative mRNA expression is presented as the fold change in $\mathrm{C} 2 \mathrm{C} 12$ cells cocultured with MSCs to C2C12 cells without coculture. Each value represents the mean \pm S.D. $(n=4)$.

(A)

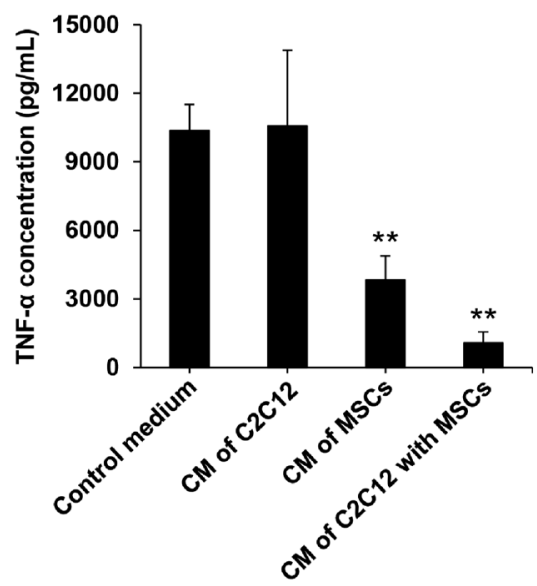

(B)

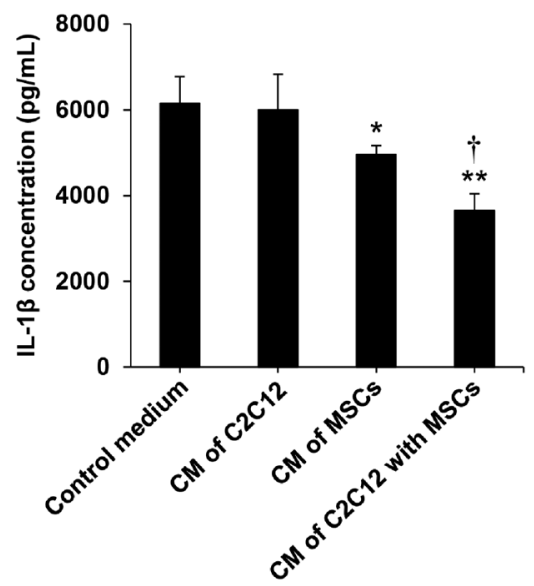

(C)

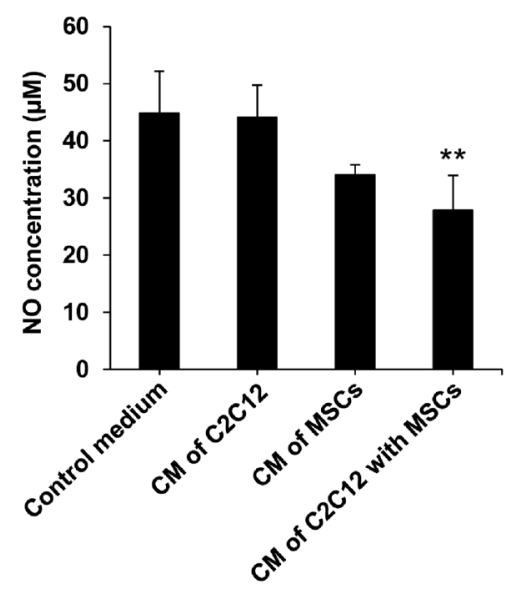

Fig. 4. Inflammatory Response of Mouse Peritoneal Macrophages in Conditioned Medium of C2C12 Cells Cocultured with MSCs under LPS Stimulation

Concentrations of TNF- $\alpha$ (A), IL-1 $\beta$ (B), and NO (C) in culture supernatants of mouse peritoneal macrophages cultured in conditioned medium (CM) of MSCs, and $\mathrm{C} 2 \mathrm{C} 12$ cells with or without coculture of MSCs under LPS stimulation $(100 \mathrm{ng} / \mathrm{mL})$. The culture supernatants were collected at $24 \mathrm{~h}$ after LPS stimulation. CM was obtained from MSCs or C2C12 cells cocultured with or without MSCs incubated for $24 \mathrm{~h}$ under LPS stimulation $(100 \mathrm{ng} / \mathrm{mL})$. Each value represents the mean + S.D. $(n=4)$. ${ }^{*} p<0.05 ; * * p<0.01$, compared with control medium. ${ }^{\dagger} p<0.05$, compared with CM of MSCs.

of IL-6 production by MAPK pathways. Moreover, all MAPK inhibitors did not significantly inhibit IL-6 production from $\mathrm{C} 2 \mathrm{C} 12$ cells in conditioned medium of MSCs. These results suggest that MAPK pathways do not greatly contribute to the enhanced expression of IL-6 in $\mathrm{C} 2 \mathrm{C} 12$ cells by the paracrine effect of MSCs. We also investigated the involvement of $\mathrm{NF}-\kappa \mathrm{B}$ and STAT3 signaling in IL-6 secretion from $\mathrm{C} 2 \mathrm{C} 12$ cells. LPS stimulates IL-6 expression in skeletal muscle cells via Toll-like receptor-4 (TLR-4)-mediated NF- $\kappa \mathrm{B}$ activation. $^{24)}$ The present study showed that BAY11-7082 exerted a significant inhibitory effect on IL-6 expression in LPSstimulated $\mathrm{C} 2 \mathrm{C} 12$ cells in conditioned medium of MSCs (Fig. $2 \mathrm{~B})$. Moreover, the increase of phosphorylated NF- $\kappa \mathrm{B}$ p 65 level was observed in $\mathrm{C} 2 \mathrm{C} 12$ cells cultured in conditioned medium of MSCs (Fig. 2D). These results indicate that the increased IL- 6 production from $\mathrm{C} 2 \mathrm{C} 12$ cells in conditioned 
medium of MSCs is mainly regulated by NF- $\kappa \mathrm{B}$. In addition, we observed that pretreatment with napabucasin suppressed production of IL-6 from $\mathrm{C} 2 \mathrm{C} 12$ cells in conditioned medium of MSCs (Fig. 2C). We also observed the increased level of phosphorylated STAT3 in $\mathrm{C} 2 \mathrm{C} 12$ cells cultured in conditioned medium of MSCs (Fig. 2E). These results suggest that STAT3 is also a little involved in the increase of IL-6 expression in C2C12 cells. Cramer et al. reported that IL-6 activates STAT3 and activated STAT3 promote the transcription of IL- $6 .{ }^{18)}$ In addition, Kim et al. demonstrated that IL-6 treatment significantly increases TLR-4 mRNA expression in differentiated human skeletal muscle myoblasts via activation of STAT3. ${ }^{25}$ ) Kim et al. also showed that IL-6-induced STAT3 signaling stimulates TLR-4 expression in L6 rat myoblasts. ${ }^{26)}$ Considering these findings, we assume that IL- 6 secreted from $\mathrm{C} 2 \mathrm{C} 12$ cells activates STAT3 in $\mathrm{C} 2 \mathrm{C} 12$ cells in an autocrine manner, resulting in the direct promotion of IL-6 transcription and/or the increase of TLR-4 expression and subsequent NF- $\kappa \mathrm{B}$ activation and IL- 6 expression in $\mathrm{C} 2 \mathrm{C} 12$ cells. Further studies are needed to determine which factors secreted from MSCs contribute to the direct or indirect activation of $\mathrm{NF}-\kappa \mathrm{B}$ and STAT3 in C2C12 cells and elucidate its mechanisms.

In addition to protein production, we examined the mRNA expression levels of proinflammatory cytokines and iNOS in LPS-stimulated $\mathrm{C} 2 \mathrm{C} 12$ cells cocultured with MSCs. Although the IL- 6 mRNA level in $\mathrm{C} 2 \mathrm{C} 12$ cells was strongly increased by coculture with MSCs, TNF- $\alpha$ and IL- $1 \beta$ mRNA levels were decreased (Figs. 3A-C), which would be a skeletal musclespecific response. Keller et al. reported that ionomycin enhances IL-6 mRNA expression in human skeletal muscle cells by elevating intracellular $\mathrm{Ca}^{2+}$, while the TNF- $\alpha$ mRNA level was decreased significantly. ${ }^{27)}$ They mentioned that this reduction in TNF- $\alpha$ expression was due to the anti-inflammatory properties of IL- 6 by an autocrine mechanism. Based on this finding, we considered that the increased IL- 6 production from $\mathrm{C} 2 \mathrm{C} 12$ cells was responsible for the inhibition of their TNF- $\alpha$ and IL- $1 \beta$ mRNA expression. In addition, we observed elevated expression of iNOS mRNA in $\mathrm{C} 2 \mathrm{C} 12$ cells cocultured with MSCs (Fig. 3D). Apart from IL-6, iNOS expression in skeletal muscle cells is also regulated by $\mathrm{NF}-\kappa \mathrm{B},{ }^{28,29)}$ and $\mathrm{NO}$ has been reported to be a crucial signaling molecule involved in skeletal muscle regeneration. ${ }^{30)}$ Rigamonti et al. demonstrated that NO activates satellite cells and enhances their proliferation and differentiation. ${ }^{31)}$ Therefore, similar to IL-6, the enhancement of iNOS expression in $\mathrm{C} 2 \mathrm{C} 12$ cells would also be a beneficial response for muscle repair.

As mentioned above, IL-6 exerts anti-inflammatory effects on immune cells. ${ }^{19,20)}$ In particular, IL-6 stimulates polarization of macrophages toward the anti-inflammatory M2 phenotype, resulting in the inhibition of proinflammatory cytokine production from macrophages. ${ }^{32,33)}$ Therefore, we assessed whether the increased IL-6 production from skeletal muscle cells by paracrine effects of MSCs suppressed the inflammatory response of macrophages. The conditioned medium of MSCs inhibited TNF- $\alpha$, IL- $1 \beta$, and NO production from LPS-stimulated macrophages (Fig. 4), which was due to the paracrine effects of MSCs on macrophages. MSCs have the capacity to elicit polarization of macrophages towards the M2 phenotype. ${ }^{34,35)}$ In addition, more significant inhibitory effects of TNF- $\alpha$, IL- $1 \beta$, and NO production from macrophages were observed when macrophages were cultured in the conditioned medium of $\mathrm{C} 2 \mathrm{C} 12$ cells cocultured with MSCs. We consider that this additional suppression of the immune response of macrophages would be attributed to the anti-inflammatory effect of IL-6 secreted from $\mathrm{C} 2 \mathrm{C} 12$ cells.

In conclusion, the present study demonstrates that MSCs stimulate IL-6 production from $\mathrm{C} 2 \mathrm{C} 12$ cells via paracrine mechanisms, and NF- $\kappa \mathrm{B}$ and STAT3 are involved in this response of $\mathrm{C} 2 \mathrm{C} 12$ cells. In addition, MSCs enhance iNOS gene expression and suppress TNF- $\alpha$ and IL- $1 \beta$ gene expression in $\mathrm{C} 2 \mathrm{C} 12$ cells. We also found that the MSC-stimulated secretion of humoral factors from $\mathrm{C} 2 \mathrm{C} 12$ cells contributes to suppression of the inflammatory response of macrophages. These findings provide valuable information to achieve effective and safe regenerative therapy of skeletal muscle using MSCs.

Acknowledgments This work was supported in part by the Ritsumeikan Global Innovation Research Organization (R-GIRO) project at Ritsumeikan University and the Uehara Memorial Foundation. We thank Mitchell Arico for editing a draft of this manuscript.

Conflict of Interest The authors declare no conflict of interest.

Supplementary Materials The online version of this article contains supplementary materials.

\section{REFERENCES}

1) Le Blanc K, Ringdén O. Immunomodulation by mesenchymal stem cells and clinical experience. J. Intern. Med., 262, 509-525 (2007).

2) Shammaa R, El-Kadiry AE, Abusarah J, Rafei M. Mesenchymal stem cells beyond regenerative medicine. Front. Cell. Dev. Biol., 8 $72(2020)$

3) Lavoie JR, Rosu-Myles M. Uncovering the secretes of mesenchymal stem cells. Biochimie, 95, 2212-2221 (2013).

4) Liang X, Ding Y, Zhang Y, Tse HF, Lian Q. Paracrine mechanisms of mesenchymal stem cell-based therapy: current status and perspectives. Cell Transplant., 23, 1045-1059 (2014).

5) Chhetri JK, de Souto Barreto P, Fougère B, Rolland Y, Vellas B Cesari M. Chronic inflammation and sarcopenia: A regenerative cell therapy perspective. Exp. Gerontol., 103, 115-123 (2018).

6) Florea V, Bagno L, Rieger AC, Hare JM. Attenuation of frailty in older adults with mesenchymal stem cells. Mech. Ageing Dev., 181, 47-58 (2019).

7) Winkler T, von Roth P, Radojewski P, Urbanski A, Hahn S, Preininger B, Duda GN, Perka C. Immediate and delayed transplantation of mesenchymal stem cells improve muscle force after skeletal muscle injury in rats. J. Tissue Eng. Regen. Med., 6 (Suppl. 3), s60-s67 (2012).

8) von Roth P, Duda GN, Radojewski P, Preininger B, Perka C, Winkler T. Mesenchymal stem cell therapy following muscle trauma leads to improved muscular regeneration in both male and female rats. Gend. Med., 9, 129-136 (2012).

9) Corona BT, Rathbone CR. Accelerated functional recovery after skeletal muscle ischemia-reperfusion injury using freshly isolated bone marrow cells. J. Surg. Res., 188, 100-109 (2014).

10) Kim MJ, Kim ZH, Kim SM, Choi YS. Conditioned medium derived from umbilical cord mesenchymal stem cells regenerates atrophied muscles. Tissue Cell, 48, 533-543 (2016).

11) Nakamura Y, Miyaki S, Ishitobi H, Matsuyama S, Nakasa T, Kamei N, Akimoto T, Higashi Y, Ochi M. Mesenchymal-stem-cell-derived exosomes accelerate skeletal muscle regeneration. FEBS Lett., 589, 1257-1265 (2015). 
12) Karalaki M, Fili S, Philippou A, Koutsilieris M. Muscle regeneration: cellular and molecular events. In Vivo, 23, 779-796 (2009).

13) Song YH, Song JL, Delafontaine P, Godard MP. The therapeutic potential of IGF-I in skeletal muscle repair. Trends Endocrinol. Metab., 24, 310-319 (2013).

14) Miller KJ, Thaloor D, Matteson S, Pavlath GK. Hepatocyte growth factor affects satellite cell activation and differentiation in regenerating skeletal muscle. Am. J. Physiol. Cell Physiol., 278, C174-C181 (2000).

15) Kono Y, Miyoshi S, Fujita T. Dextran sodium sulfate alters cytokine production in macrophages in vitro. Pharmazie, 71, 619-624 (2016).

16) Frost RA, Nystrom GJ, Lang CH. Lipopolysaccharide and proinflammatory cytokines stimulate interleukin-6 expression in $\mathrm{C} 2 \mathrm{C} 12$ myoblasts: role of the Jun $\mathrm{NH}_{2}$-terminal kinase. Am. J. Physiol. Regul. Integr. Comp. Physiol., 285, R1153-R1164 (2003).

17) Kim JA, Park HS, Kang SR, Park KI, Lee DH, Nagappan A, Shin SC, Lee WS, Kim EH, Kim GS. Suppressive effect of flavonoids from Korean Citrus aurantium L. on the expression of inflammatory mediators in L6 skeletal muscle cells. Phytother. Res., 26, 1904-1912 (2012).

18) Cramer Z, Sadek J, Vazquez GG, Di Marco SD, Pause A, Pelletier J, Gallouzi IE. eIF4A inhibition prevents the onset of cytokine-induced muscle wasting by blocking the STAT3 and iNOS pathways. Sci. Rep., 8, 8414 (2018).

19) Scheller J, Chalaris A, Schmidt-Arras D, Rose-John S. The pro- and anti-inflammatory properties of the cytokine interleukin-6. Biochim. Biophys. Acta, 1813, 878-888 (2011).

20) Pal M, Febbraio MA, Whitham M. From cytokine to myokine: the emerging role of interleukin-6 in metabolic regulation. Immunol. Cell Biol., 92, 331-339 (2014).

21) Serrano AL, Baeza-Raja B, Perdiguero E, Jardí M, Muñoz-Cánoves P. Interleukin- 6 is an essential regulator of satellite cell-mediated skeletal muscle hypertrophy. Cell Metab., 7, 33-44 (2008).

22) Hoene M, Runge H, Häring HU, Schleicher ED, Weigert C. Interleukin-6 promotes myogenic differentiation of mouse skeletal muscle cells: role of the STAT3 pathway. Am. J. Physiol. Cell Physiol., 304, C128-C136 (2013).

23) Tierney MT, Aydogdu T, Sala D, Malecova B, Gatto S, Puri PL, Latella L, Sacco A. STAT3 signaling controls satellite cell expansion and skeletal muscle repair. Nat. Med., 20, 1182-1186 (2014).

24) Liang H, Hussey SE, Sanchez-Avila A, Tantiwong P, Musi N. Effect of lipopolysaccharide on inflammation and insulin action in human muscle. PLOS ONE, 8, e63983 (2013).
25) Kim TH, Choi SE, Ha ES, Jung JG, Han SJ, Kim HJ, Kim DJ, Kang Y, Lee KW. IL-6 induction of TLR-4 gene expression via STAT3 has an effect on insulin resistance in human skeletal muscle. Acta Diabetol., 50, 189-200 (2013).

26) Kim M, Song K, Kim YS. Alantolactone improves prolonged exposure of interleukin-6-induced skeletal muscle inflammation associated glucose intolerance and insulin resistance. Front. Pharmacol., 8, 405 (2017).

27) Keller C, Hellsten Y, Steensberg A, Pedersen BK. Differential regulation of IL-6 and TNF- $\alpha$ via calcineurin in human skeletal muscle cells. Cytokine, 36, 141-147 (2006).

28) Adams V, Nehrhoff B, Späte U, Linke A, Schulze PC, Baur A, Gielen S, Hambrecht R, Schuler G. Induction of iNOS expression in skeletal muscle by IL- $\beta$ and $\mathrm{NF} \kappa \mathrm{B}$ activation: an in vitro and in vivo study. Cardiovasc. Res., 54, 95-104 (2002).

29) Ji LL, Gomez-Cabrera MC, Vina J. Role of nuclear factor $\kappa \mathrm{B}$ and mitogen-activated protein kinase signaling in exercise-induced antioxidant enzyme adaptation. Appl. Physiol. Nutr. Metab., 32, 930-935 (2007).

30) Filippin LI, Moreira AJ, Marroni NP, Xavier RM. Nitric oxide and repair of skeletal muscle injury. Nitric Oxide, 21, 157-163 (2009).

31) Rigamonti E, Touvier T, Clementi E, Manfredi AA, Brunelli S, Rovere-Querini P. Requirement of inducible nitric oxide synthase for skeletal muscle regeneration after acute damage. J. Immunol., 190, 1767-1777 (2013).

32) Braune J, Weyer U, Hobusch C, Mauer J, Brüning JC, Bechmann I, Gericke M. IL-6 regulates M2 polarization and local proliferation of adipose tissue macrophages in obesity. J. Immunol., 198, 29272934 (2017)

33) Yin Z, Ma T, Lin Y, Lu X, Zhang C, Chen S, Jian Z. IL-6/STAT3 pathway intermediates M1/M2 macrophage polarization during the development of hepatocellular carcinoma. J. Cell. Biochem., 119, 9419-9432 (2018).

34) Yuan Y, Li L, Zhu L, Liu F, Tang X, Liao G, Liu J, Cheng J, Chen Y, Lu Y. Mesenchymal stem cells elicit macrophages into M2 phenotype via improving transcription factor EB-mediated autophagy to alleviate diabetic nephropathy. Stem Cells, 38, 639-652 (2020).

35) Lu X, Li N, Zhao L, Guo D, Yi H, Yang L, Liu X, Sun D, Nian H, Wei R. Human umbilical cord mesenchymal stem cells alleviate ongoing autoimmune dacryoadenitis in rabbits via polarizing macrophages into an anti-inflammatory phenotype. Exp. Eye Res., 191, 107905 (2020). 